\title{
Thoracic aortic involvement in cystic echinococcosis: A case report
}

Mohammad Mahdi Kamyar ${ }^{1}$, Hassan Ravari ${ }^{2}$

${ }^{1}$ M.D., General Surgeon, Fellow, Vascular and Endovascular Surgery Research Center, Alavi Hospital, Faculty of Medicine, Mashhad University of Medical Sciences, Mashhad, Iran

${ }^{2}$ M.D., Vascular Surgeon, Associate Professor, Vascular and Endovascular Surgery Research Center, Alavi Hospital, Faculty of Medicine, Mashhad University of Medical Sciences, Mashhad, Iran

Type of article: Case report

\begin{abstract}
Cystic echinococcosis is a common parasitic disease in some areas and involves different organs with different presentations. Rural areas in our country are endemic with this disease. We present a case of echinococcal aortic involvement that was diagnosed incidentally by a routine chest radiogram as a mediastinal mass. Cystic echinococcosis was established as final diagnosis after magnetic resonance imaging (MRI) and ELISA studies. The patient was treated surgically through a thoracotomy and her aortic defect was repaired during the operation. She has been asymptomatic and complication free in physical examination and imaging study in follow up periods after two years. Awareness of various presentations of the disease is necessary for physicians who are occupied in endemic areas. It is rational to treat echinococcal cysts adjacent to the great vessels with the cooperation of a vascular surgeon.

Keywords: Aorta, Echinococcosis, Hydatid Cyst, Hydatidosis, Hydatid Cyst
\end{abstract}

\section{Introduction}

Cystic echinococcosis is a parasitic disease which may involve different organs in the human body (1). Awareness of its manifestations and treatment in different organs will be helpful in accurate management of the disease (2) and help the physician to be more alert about probable complications. We encountered a patient who referred responsibly to our vascular surgery clinic due to proximity (but not relation) of her cystic mass to the thoracic aorta. Surgical treatment of the patient without readiness and vascular surgery skills could lead to a tragedy for the patient.

\section{Case presentation}

\subsection{Clinical presentation}

A 51-year-old female was referred to the vascular surgery clinic for a mediastinal cystic mass in the vicinity of the descending thoracic aorta, in magnetic resonance imaging (MRI) images. The patient was asymptomatic and the mass was found first time, incidentally, in her chest radiography behind the heart shadow.

\subsection{History}

The patient has resided in an urban area and had no history of any disease. She also had no familial history of mediastinal mass or malignancies.

\subsection{Laboratory and imaging findings}

MRI images revealed a cystic mass in the posterior mediastinum adherent to the descending thoracic aorta that pushed the heart and aorta anteriorly. Septa and daughter cysts were seen in T2 weighted images of the MRI exam (Figure 1). So, mediastinal hydatidosis (hydatid cyst) was diagnosed for the lesion. Also in T1 weighted images that

\section{Corresponding author:}

Associate Professor Dr. Hassan Ravari, Vascular and Endovascular Surgery Research Center, Alavi Hospital, Faculty of Medicine, Mashhad University of Medical Sciences, Mashhad, Iran.

Tel: +98.5138047, Email: ravarih@mums.ac.ir

Received: July 19, 2016, Accepted: December 12, 2016, Published: September 2017

iThenticate screening: August 28, 2016, English editing: May 18, 2017, Quality control: June 25, 2017

(C) 2017 The Authors. This is an open access article under the terms of the Creative Commons Attribution-NonCommercialNoDerivs License, which permits use and distribution in any medium, provided the original work is properly cited, the use is non-commercial and no modifications or adaptations are made. 
were obtained after contrast (Gadolinium) injection, no relation was found between cyst cavity and aortic lumen. After imaging studies, the diagnosis of cystic echinococcosis was established by serologic ELISA exam.

\subsection{Treatment}

After left posterolateral thoracotomy the aorta was identified and controlled proximally and distally to the cystic mass according to its very close adherence to the aorta. Hypertonic saline was injected in to the cyst and then the cyst was opened and daughter cysts and a clear fluid were evacuated. Several moments later and after decreasing in cyst pressure, severe hemorrhage occurred in the cyst cavity, so the cyst was packed and the aorta was cross clamped proximal and distal to the cyst. Inspection of the cyst cavity was done and a $10 \times 20 \mathrm{~mm}$ oval defect with smooth edges was found. The aortic wall adjacent to the defect was intact and had no inflammation or erosion. The defect was repaired by a polytetrafluoroethylene (PTFE) patch (Figure 2). The patient was discharged from hospital one week later. Treatment with albendazole was continued for three 14-day periods.

\subsection{Follow up}

The patient was followed up in 6-month periods. After two years the patient was asymptomatic and a computed tomography (CT) exam with intravenous contrast revealed normal thoracic aorta without any stenosis, aneurysm formation, or pseudoaneurysm.

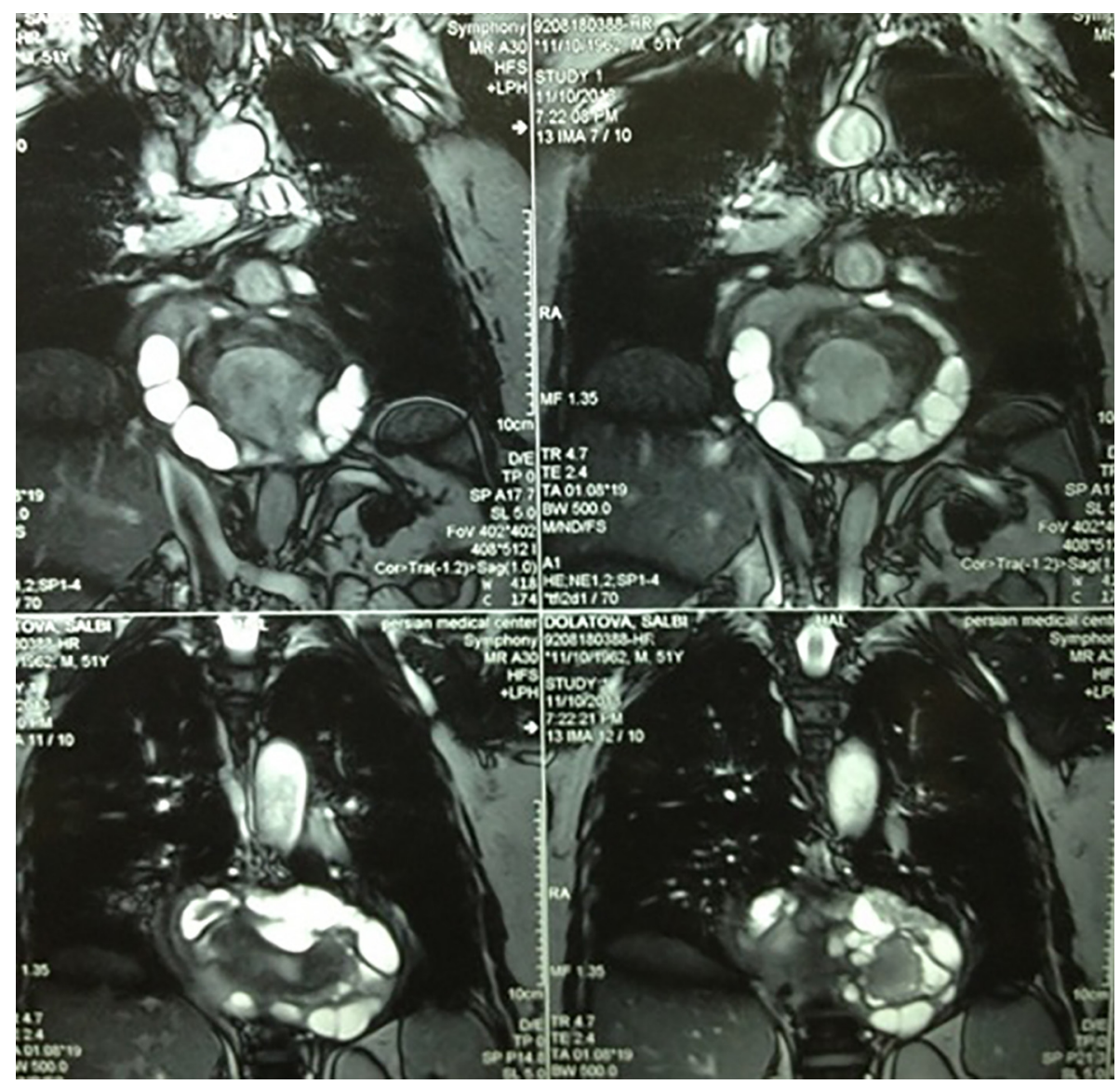

Figure 1. MRI images of mediastinal mass 


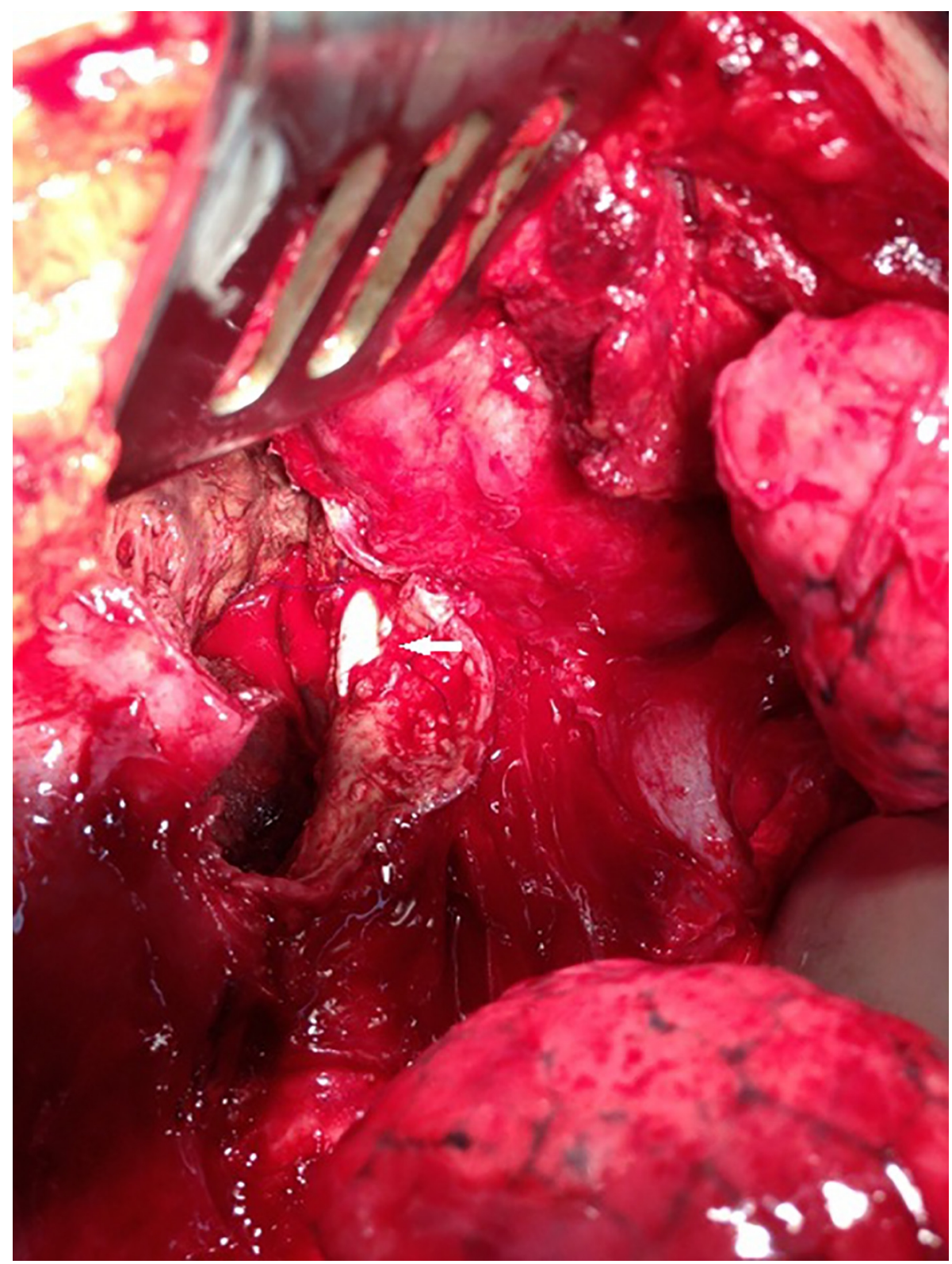

Figure 2. Aortic defect in the cavity of the cyst that repaired by PTFE patch

\section{Discussion}

Cystic echinococcosis is prevalent in rural areas in which livestock raising is common. In endemic regions, different manifestations of the disease are seen that all of them are due to larval stage of the echinococcus granulosus life cycle (1). The liver and lung are the most commonly involved organs in echinococcal infestation, but involvement of other organs has been reported. Spleen, pancreas, kidney, adrenal gland, bone, gonads, muscles, brain, heart, vessels, and subcutaneous tissues may be involved by this parasitic disease (2). The aortic wall may be involved primarily and the disease may progress in its layers (3-6). The aortic wall may also be involved secondary to invasion of the cyst from adjacent tissues $(7,8)$ similar to that which we had encountered. Aortic involvement may display as pseudoaneurysm (7-9), organ ischemia due to aortic occlusion $(5,6)$, remote ischemia due to daughter cysts embolization $(10,11,12)$, simple cystic mass (3), or even aortobronchial fistula (12). Treatment in all patients with aortic involvement consists of surgical resection of the cyst and its content, and long-term medical therapy. Vascular reconstruction must be considered and planned before surgery. In our case, the cyst cavity was not related to the aortic lumen according to MRI images, but aortic hemorrhage occurred after a decrease in cyst pressure. 


\section{Conclusions}

In endemic areas cystic echinococcosis should be considered as an important differential diagnosis for each cystic mass. Physicians should be aware about its manifestations and complications of uncommon organs involvement. It is better to do surgical treatment with complete readiness and cooperation of a vascular surgeon when the cyst is adjacent to the great vessels.

\section{Acknowledgments:}

The authors thank Dr. Mannani for his great help in the performance of the operative surgery. The authors didn't use any fund or grant for this study.

\section{Conflict of Interest:}

There is no conflict of interest to be declared.

\section{Authors' contributions:}

Both authors contributed to this project and article equally. Both authors read and approved the final manuscript.

\section{References:}

1) King CH, Fairely JK. Tapeworms (Cestodes) In Bennett JE, Dolin R, Blaser MJ, editors. Mandell, Douglas, and Bennett's principles and practice of infectious diseases. 8th ed. Philadelphia: Elsevier. 2015; 3227-36.

2) Wani RA, Wani I, Malik AA, Parray FQ, Wani AA, Dar AM. Hydatid disease at unusual sites. Int J Case Rep Imag. 2012; 3(6): 1-6. doi: 10.5348/ijcri201206128RA1.

3) Hendaoui L, Siala M, Fourati A, Thameur MH, Hamza R. Case Report: hydatide cyst of the aorta. Clin Radiol. 1991; 43(6): 423-5. doi: 10.1016/S0009-9260(05)80576-8. PMID: 2070588.

4) Pulathan Z, Cay A, Guven Y, Sarihan H. Hydatid Cyst of the Abdominal Aorta and Common Iliac Arteries Complicated by a False Aneurysm: A Case Report. J Pediatr Surg. 2004; 39(4): 637-9. PMID: 15065047.

5) Kaynak M, Koksal C, Arslan C. Hydatid Disease of the Abdominal Aorta Mimicking Leriche Syndrome. EJVES extra. 2002; 3(1): 4-5. doi: 10.1053/ejvx.2002.0110.

6) Men S, Yücesoy C, Edgüer TR, Hekimoglu B. Intraaortic Growth of Hydatid Cysts Causing Occlusion of the Aorta and of Both Iliac Arteries: Case Report. Radiology. 1999; 213(1): 192-4. doi: 10.1148/radiology.213.1.r99oc35192. PMID: 10540661.

7) Gerber BL, Pasquet A, El Khoury G, Verhelst R, Vanoverschelde J, Watremez C, et al. Echinococcosis of the Heart and Ascending Aorta. Circulation. 2012; 125(1): 185-7. doi: 10.1161/CIRCULATIONAHA.111.043893.

8) Apaydin AZ, Oguz E, Zoghi M. Hydatid cyst involving the aortic arch. Eur J Cardiothorac Surg. 2007; 31(3): 558-60. doi: 10.1016/j.ejcts.2006.11.044.

9) Zakhariev T, Stankev M, Baev B, Iliev R, Tschirkov A. Arare case of hydatid cyst perceived as false aneurysm of thoracic aorta. J Thorac Cardiovasc Surg. 1997; 113(4): 792-3. doi: 10.1016/S00225223(97)70239-3. PMID: 9104990.

10) Tosya A, Uymaz B, Celebi S, Aybek T. A rare presentation of cystic echinococcosis: aortic involvement. Interact Cardiovasc Thorac Surg. 2015; 21(4): 548-9. doi: 10.1093/icvts/ivv153. PMID: 26180090.

11) Bozok Ş, Ozan Karakisi S, Yılmaz Y, Ergene Ş, Tüfekçi N, Karamustafa H, et al. Peripheral arterial embolism due to involvement of the aortic arch with hydatid cyst. Vasa. 2015; 44(3): 237-9. doi: 10.1024/0301-1526/a000435. PMID: 26098329.

12) Buchholz S, Sowden D, Stapleton T, Pohlner P, Wright C. Massive haemoptysis due to aortobronchial fistula caused by pulmonary hydatidosis. Med J Aust. 2009; 190(4): 222. PMID: 19220197. 